\title{
Applying Biopharmaceutical Classification System (BCS) Criteria to Predict Oral Absorption of Drugs in Dogs: Challenges and Pitfalls
}

\author{
Mark G. Papich ${ }^{1,3}$ and Marilyn N. Martinez ${ }^{2}$
}

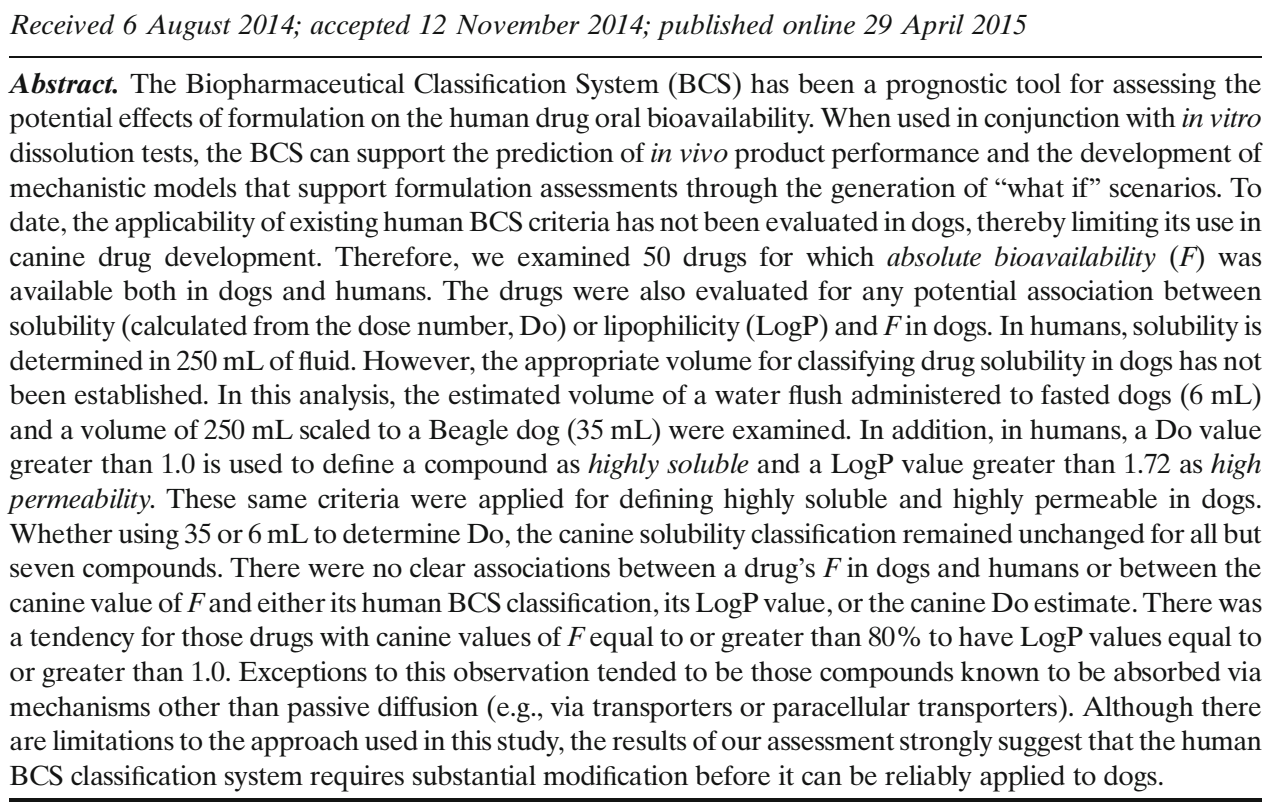

KEY WORDS: BCS; dogs; canine; permeability; solubility.

\section{INTRODUCTION}

The United States Pharmacopeial Convention (USP) authorized the creation of an advisory panel to investigate the possibility of applying the principles of the Biopharmaceutics Classification System (BCS) to veterinary drugs-specifically, solid oral formulations administered to dogs (1). Developed for human pharmaceutical compounds (2-6), the BCS is an important tool that facilitates product development and regulatory decisions. By understanding the solubility of a compound in biorelevant media and its permeability across biological membranes, the rate limiting factors determining the rate and extent of oral drug absorption can be identified. This information can be invaluable for predicting the potential influence of formulation and physiological variables on oral drug bioavailability.

\footnotetext{
${ }^{1}$ College of Veterinary Medicine, North Carolina State University, 1060 William Moore Drive, Raleigh, North Carolina 27607, USA.

${ }^{2}$ Center for Veterinary Medicine, US Food and Drug Administration, 7500 Standish Place, HFV-100, Rockville, Maryland 20855, USA.

${ }^{3}$ To whom correspondence should be addressed. (e-mail: mgpapich@ncsu.edu)
}

Within the framework of human pharmaceuticals, drugs can be classified into one of the following four BCS categories:

Class I: high solubility, high permeability: generally very well-absorbed compounds

Class II: low solubility, high permeability: exhibits dissolution rate-limited absorption

Class III: high solubility, low permeability: exhibits permeability-limited absorption

Class IV: low solubility, low permeability: very poor oral bioavailability

A complementary classification system was proposed by Wu and Benet $(7,8)$. They recognized that drugs exhibiting high permeability are generally extensively metabolized, while poorly permeable compounds are primarily eliminated as unchanged drug in the bile and urine. Thus, the Biopharmaceutical Drug Disposition Classification System (BDDCS) has been used to predict drug disposition and potential drugdrug interactions in the intestine and the liver and potentially the kidney and brain. Although the solubility criteria for the BCS and BDDCS are the same, there is a substantial difference in the second variable being considered. For the 
BDDCS, the second classification is related to the extent of drug metabolism. Conversely, the assessment of permeability in the BCS is linked to the extent of intestinal absorption, i.e., a drug is considered to be highly permeable when the extent of the systemic absorption (parent drug plus metabolites) in humans is determined to be at least $90 \%$ of an administered dose based on a mass balance determination or in comparison to an intravenous reference dose. Accordingly, the BCS and BDDCS classification of a drug may differ.

The US Food and Drug Administration's (FDA's) Center for Drug Evaluation and Research (CDER) (9) has incorporated BCS concepts into guidance documents for human medications into the 2000 FDA Guidance for Industry, including guidance for the waiver of in vivo bioequivalence study requirements for high solubility/high permeability drug products. However, the BCS has not as yet been extrapolated for application to veterinary drugs. The reason for this gap is that the BCS was developed based upon human digestive physiology, which can be vastly different from that observed in veterinary species. Given the similarity of therapeutic entities used in the dogs and humans, and because of the use of the dog as a preclinical species for human medicine (10), it would be of particular value to have an understanding of how the BCS criteria can be translated between human and canine gastrointestinal (GI) physiologies.

The solubility criteria used both by the BCS and the BDDCS rely upon formulation considerations in that it is based upon the highest dose that will be administered. Both the BCS and the BDDCS define a high solubility compound at the highest marketed dose strength that is soluble in $250 \mathrm{~mL}$ of water over the $\mathrm{pH}$ range of $1-7.5$ at $37^{\circ} \mathrm{C}$. This definition differs from that of "intrinsic solubility," which reflects the equilibrium aqueous solubility of a compound. For acids and bases, intrinsic solubility represents the concentration of the unionized species in a saturated solution at the $\mathrm{pH}$ value where that compound is fully unionized (11). While there has been some debate regarding certain compounds whose intrinsic solubility may not be accurately defined when using conventional media $(12,13)$, those considerations are founded upon the perspective of a drug's physicochemical characteristics rather than on the in vivo conditions into which that drug will be introduced. Thus, while intrinsic solubility is solely a function of the molecule, the BCS (or BDDCS)-based solubility criteria is dependent upon physiological conditions and the corresponding targeted therapeutic dose. Unfortunately, what constitutes the BCSbased criteria for high or low solubility is currently undefined for dogs because of complexities associated with interspecies differences in the composition of the GI milieu (1).

Another obstacle confronted when trying to establish canine-specific BCS criteria is the challenge associated with the classification of intestinal permeability. Despite the range of high throughput systems available for examining human intestinal permeability, such as Caco-2 cells, parallel artificial membrane permeability assay (PAMPA), and phospholipid vesicle-based permeation assay (PVPA), these methods for estimating drug permeability have only been applied to human drugs $(14,15)$. These systems have not been developed and validated for application to drug permeability across the canine intestine $(16,17)$. Moreover, while one may argue that transcellular permeability should be similar in humans and dogs, the GI tract of the dog tends to be more permeable (leakier) because of the larger intercellular pores (18).

Currently, the existing in vitro methods for evaluating drug permeability have not succeeded in providing data that can be extrapolated to dogs. For this reason, we needed to resort to comparisons based upon the use of absolute bioavailability. Because there are no suitable in vitro methods to assess effective permeability in dogs (Peff), we have used absolute bioavailability $(F)$ for this analysis. We have justified this approach because a comparison of drug absorption across human colonic epithelium cell layers (Caco-2 cell line) to absorption across canine colon tissue did not show a relationship (19). The Ussing chamber technique, which has been evaluated for other veterinary species (20), has not been applicable for canine studies (21) because of the fragility of the tissue. Membrane damage that occurs prevents permeability measurements using this technique in dogs (21). Therefore, without the availability of these in vitro tools, other data must be used to predict permeability and apply BCS criteria for oral drugs administered to dogs.

The current investigation was undertaken because of the lack of established BCS criteria to evaluate oral medications administered to dogs. The objectives were to examine the properties that define human BCS criteria for drugs and to compare this information to pharmacokinetic data available from studies in dogs. Without in vitro intestinal permeability data in dogs, another parameter must be considered to classify a drug as either high or low permeability. To this end, there are numerous molecular factors that impact drug transcellular permeability, including hydrogen bonding properties, molecular size and shape, polarity, flexibility, and ionization properties $(22,23)$. There is no "gold standard" or [even a suggested criterion based upon the log of the lipophilicity coefficient ( $\log \mathrm{P}) \mathrm{pH}$-dependent lipophilicity value $(\log \mathrm{D})]$ that has been proposed as a cutoff value. Therefore, we focused on the use of the systemic absorption value (absolute bioavailability, $F$ ), which we were able to obtain from the published literature. It was assumed that if the value of $F$ is high, permeability (via active or passive processes) must likewise be high. We also acknowledged at the outset that the converse was not necessarily true and that the use of $F$ as an indicator of drug permeability will produce some false negative results, i.e., there are drugs that have high permeability, but low values of $F$ because of other factors such as intestinal efflux or high first-pass metabolism.

A drug solubility classification has not been established for medications administered to dogs $(24,25)$. To classify a drug as either high or low solubility in dogs requires that one knows the ideal volume in which to measure solubility. In this study, we have examined two different volumes and considered whether this parameter can be useful to predict oral absorption of medications in dogs.

Ultimately, the objective of this study was to identify the in vitro drug properties with respect to their potential impact on dog-human differences and similarities on oral drug solubility and permeability. The foundational assumption was that if properties can be identified, we could then generate dog-specific criteria for applying BCS concepts to understand the critical formulation and physiological 
variables that can influence canine oral drug absorption. Similar to its tremendous influence on human drug product development and regulatory evaluation, a roadmap for screening oral product formulations, if applied to veterinary drug products, would provide a tool for screening new formulations. Additional benefits that would be associated with a canine-specific BCS would be an improvement on our ability to compare human formulations for potential testing and clinical use based upon information obtained in dogs (and vice versa).

One of our objectives was to extend our assessment beyond the results reported by Chiou et al., (26) in which the oral bioavailability of 43 compounds was compared in humans and dogs. In that study, they observed that while 22 of the 43 compounds were completely absorbed in both humans and dogs, the overall interspecies correlation of $F$ values was low (coefficient of determination, $R^{2}=0.51$ ). A pitfall associated with the investigation by Chiou et al. was that much of the data were based upon radiolabeled data, thereby precluding a differentiation between parent compound and metabolites. Given the potential for interspecies differences in intestinal metabolism, and since $F$ values were based on total urinary recovery of radioactivity of the drug (thereby further confounding the comparison with potential differences in post-absorption processes), we could not use that information to generate predictions on the permeability component of the BCS. However, we also recognized that a drug with a high first-pass effect may be reported with high $F$ in the study by Chiou et al. (26), but not in our study reported. Thus, in addition to evaluation of BCS classification versus $F$ in dogs and humans, we compared our $F$ values with those reported by Chiou et al. (26).

\section{EXPERIMENTAL METHODS}

To explore the potential application of BCS principles for oral drugs administered to dogs, pharmacokinetic, lipophilicity, and solubility data were either calculated or were obtained from existing literature. Lipophilicity, calculated as the octanol / water partition coefficient $(\log \mathrm{P})$ was used to estimate permeability because there is no in vitro permeability data available for dogs, we used the experimental $\log \mathrm{P}$ values (which consider the ratio of unionized solute concentrations in octanol versus that in water), rather than Log D (which is ratio of the concentration of drug in octanol versus the sum of the concentration of both the neutral and ionized moieties in water) primarily because we found the $\log \mathrm{P}$ values to be more readily available for all 50 compounds in our study and because $\log \mathrm{P}$ had previously been included as a surrogate for predicting the intestinal permeability for human drugs (3-6). The list of drugs for which human BCS criteria were already derived was used as a starting database (3-6). Values for current BCS classification, solubility (expressed as $\mathrm{mg} / \mathrm{mL}$ ), and $\log \mathrm{P}$ were obtained from an internet web site that lists these criteria (Therapeutic Systems Research Laboratories (TSRL), Inc; http://tsrlinc.com/resources/services/) (27). Solubility data $(\mathrm{mg} / \mathrm{mL})$ and $\operatorname{LogP}$ estimates were also obtained from the literature (3-6). From the hundreds of drugs listed in the references cited above, the literature was searched for data on oral absorption of those compounds for which we were able to obtain data in dogs.
The $F$ values for dogs were obtained from published sources, the manufacturer's data (approved drug label), or in some instances from the author's unpublished research. Although we found additional published information on the oral bioavailability for some veterinary drugs (28), human data and human BCS criteria were not available for these veterinary-specific drugs, and therefore, these compounds were excluded from our analysis.

With respect to classification of drug solubility, one of the challenges was the absence of the ideal canine gastric volume that can be used for estimating a dose number (Do). The Do used in the calculations for determining BCS criteria is determined by the formula:

Do $=\frac{(M / V)}{C}$

where $M$ is the dose strength of the tablet/capsule, $V$ is the volume administered (defined as $250 \mathrm{~mL}$ for humans), and $C$ is the drug's solubility $(\mathrm{mg} / \mathrm{mL})$.

A volume of $250 \mathrm{~mL}$, the typical volume of water consumed during human bioavailability studies, is too large to be appropriate to estimate the volume of water flush administered to a fasted dog. Therefore, other volumes were explored for the calculation of a Do. In one analysis, we used a volume of $6 \mathrm{~mL}$ because this is often the volume administered to dogs with an oral medication (a single "flush" with a 6-mL syringe). A volume of $6 \mathrm{~mL}$ also has been suggested as the residual volume in the empty canine stomach $(1,24,25)$. Additional analysis was performed using $35 \mathrm{~mL}$ because it is equivalent to the $250 \mathrm{~mL}$ ( one cup) when scaled to the size of an average Beagle dog (the breed used most often in oral drug absorption studies).

The relationships between canine estimates of $F$ versus human BCS values, solubility, LogP, Do, and $F$ values for humans were compared by linear regression. This was accomplished using the Proc Reg procedure in SAS (version 9.3). Both slope and intercepts were included in the regression equation. Confidence and prediction intervals about the regression line were set at alpha $=0.10 \quad(90 \%$ intervals, $5 \%$ in each tail). The regression of Do on $F$ was expressed relative to the natural logarithm of Do (LD). This evaluation was conducted both at Do values estimated at a volume of $6 \mathrm{~mL}$ (LD6) and $35 \mathrm{~mL}$ (LD35).

\section{RESULTS}

Oral absorption data were obtained for 50 drugs for which human and canine data were available (29-36; Papich, 1986, Pharmacokinetics of ranitidine and cimetidine in dogs, unpublished data; 37-47; Papich, 1988, Pharmacokinetics of doxycycline in dogs after intravenous administration and oral administration of doxycycline hyclate and doxycycline monohydrate, unpublished data; 48-59; Papich, 1986, Pharmacokinetics of lorazepam in dogs, unpublished data; 60-75). Four drugs had conflicting data and therefore were listed twice to include both sets of data. For two drugs $(38,48)$, publications addressing BCS biowaivers for human formulations had data that conflicted with an official web site (27) or other published data (3-6). These drugs were listed twice to 
accommodate both data. Many of these drugs were administered to dogs as the human formulation or as a compounded product when there was no approved veterinary counterpart. For two drugs (furosemide and phenobarbital), two sets of canine values were considered because of duplication of published data. There was a relatively even distribution of drugs among the four BCS classes. There were 16 drugs from class I, 9 drugs from class II, 15 drugs from class III, and 10 drugs from class IV. As a percentage of drugs, this was a higher representation of class III and class IV drugs than the analysis of Takagi et al. (6).

Table I summarizes the information used in our examination of the relationships between drug physicochemical parameters and the oral absorption performance in humans and dogs. For consistency, we relied primarily upon two sources of information for the BCS classification: Kasim et al. (5), using their LogP-based estimates for our predictions of drug permeability, and $\mathrm{Wu}$ and Benet (7). For those several compounds that were not contained within those two references, other published values were used $(3,4,6,76)$. Despite recognized diversity in some of the values across these various information sources, we concluded that since the magnitude of differences was small relative to the overall strength of the trends that were observed, any error that may have been introduced by the selection of publications would not influence the conclusions derived from our comparison.

When assessing the relationship between estimates of $F$ in dogs and humans (Fig. 1), we observed that the slope significantly differed from zero $(P=0.0055)$. However, the corresponding low coefficient of determination $\left(R^{2}=0.15\right)$ indicates that human estimates of $F$ very poorly predicted canine $F$ values. Without considering drug physicochemical characteristics, the potential contribution of drug solubility and/or permeability on the observed interspecies inconsistencies could be determined (and hence, the reason behind our further examination of these data). The intercept of the regression line was 0.31 , which might be construed as suggesting a trend toward higher canine drug bioavailability when the human oral drug bioavailability is very low. Indeed, of the nine drugs with human estimates of $F$ less than 0.40 , six were associated with canine $F$ values equal to or greater than that observed in humans. However, given the very low $R^{2}$ value, such conclusions should be construed as an overinterpretation of the observed canine/human relationship. Along with this caution is the observation of wider confidence and predictions toward the intercept.

Despite the low overall correlation between human and canine $F$ values, when segregated according to its BCS class relationship, patterns begin to emerge (Fig. 2a-d). We observe that as compared to that observed in BCS classes III and IV, many of the compounds contained in BCS classes I and II demonstrated a good correlation between $F$ in dogs and humans. In terms of the percent of the listed compounds where the human and canine $F$ values differed by no more than $+/-20 \%$, these were found to be $79,64,36$, and $20 \%$ for BCS classes I-IV, respectively (Table II). For BCS class I compounds, we observed a trend toward a lower bioavailability in dogs as compared to that in humans (Fig. 2a). Similarly, the class IV compounds tended to exhibit a comparatively lower oral bioavailability in dogs (Fig. 2d). For the nonsteroidal anti-inflammatory drugs (NSAIDs), all but one showed similar $F$ values in dogs and humans (four were in class II or IV), which is consistent with their BCS classification of a low solubility compound being primarily a function of their behavior in acid. A surprisingly high number of drugs in class II (Fig. 2c) showed similar or higher $F$ values in dogs compared to humans. Several of these compounds were weak bases.

As compared to that seen for BCS classes I and II, far fewer compounds exhibited comparable human versus dog bioavailability for BCS classes III and IV. With regard to the latter two classes, there was no obvious pattern identified such that very high or very low oral absorption could be correlated with values of $F$ when comparing dogs to humans. For example, for class III drugs (Fig. 2c), there was somewhat of an even distribution above and below a line of unity. There were examples of some compounds that were more bioavailable in humans than in dogs (e.g., codeine), while others were more bioavailable in dogs than humans (e.g., ranitidine).

One of the potential sources of interspecies bias is the difference in gastric volume versus dose. For this reason, we estimated the Do, using a volume of 6 or $35 \mathrm{~mL}$ (representing a range of volumes administered in studies where dogs are administered a water flush after oral dose administration). As shown in Fig. 3a (6 mL volume) and b (35 mL volume), no obvious association between the calculated Do (expressed as LD) and $F$ could be identified. This is evidenced both by low $R^{2}$ values (0.031 and 0.029 and for $35 \mathrm{~mL}$ (LD35) and $6 \mathrm{~mL}$ (LD6), respectively) and the lack of statistical significance when evaluating the slope of the regression line $(P=0.23$ and 0.22 for $3 a$ and $b$, respectively), indicating that these slopes do not significantly differ from zero. Furthermore, the similarity in width of the confidence and prediction intervals at the upper and lower portions of the profile suggests that the error about the regression line is similar across the range of LD values obtained in this study.

Figure $3 a, b$ illustrates that regardless of whether a volume of 6 or $35 \mathrm{~mL}$ was used in the analysis, there was little influence of fluid volume on Do above, or below, 1.0. This indicates that either volume could adequately reflect oral dose solubility as a function of administered dose for most drugs administered to dogs. Using a Do of 1.0 as the cutoff between low and high solubility (as used for the human BCS), only seven drugs (gabapentin, cimetidine, amlodipine, ciprofloxacin, sildenafil, theophylline, and atenolol) would be classified as high solubility $(\mathrm{Do}<1)$ using a volume of $35 \mathrm{~mL}$, but low solubility (Do $>1$ ) using a volume of $6 \mathrm{~mL}$.

The influence of the lipophilicity (expressed as $\log \mathrm{P}$ ) on $F$ was examined in Fig. 4. When considering all of the drugs included in this analysis, no association could be identified between $\log \mathrm{P}$ and $F\left(R^{2}=0.0027\right)$. The large $P$ value for the slope of the regression line $(P=0.72)$ indicates that the slope defining the regression of $\log \mathrm{P}$ on canine $F$ is not significantly different from zero. Furthermore, similarities in the width of the confidence and prediction intervals at the upper and lower portions of the profile suggest that that the error about the regression line was similar across the range of LogP values. However, limiting our assessments to those drugs with $F>0.80$ (Fig. 5), most had LogP values within the range of $0-4$, suggesting transcellular absorption. The only compounds showing high $F$ values but $\log \mathrm{P}<0$ in dogs were 


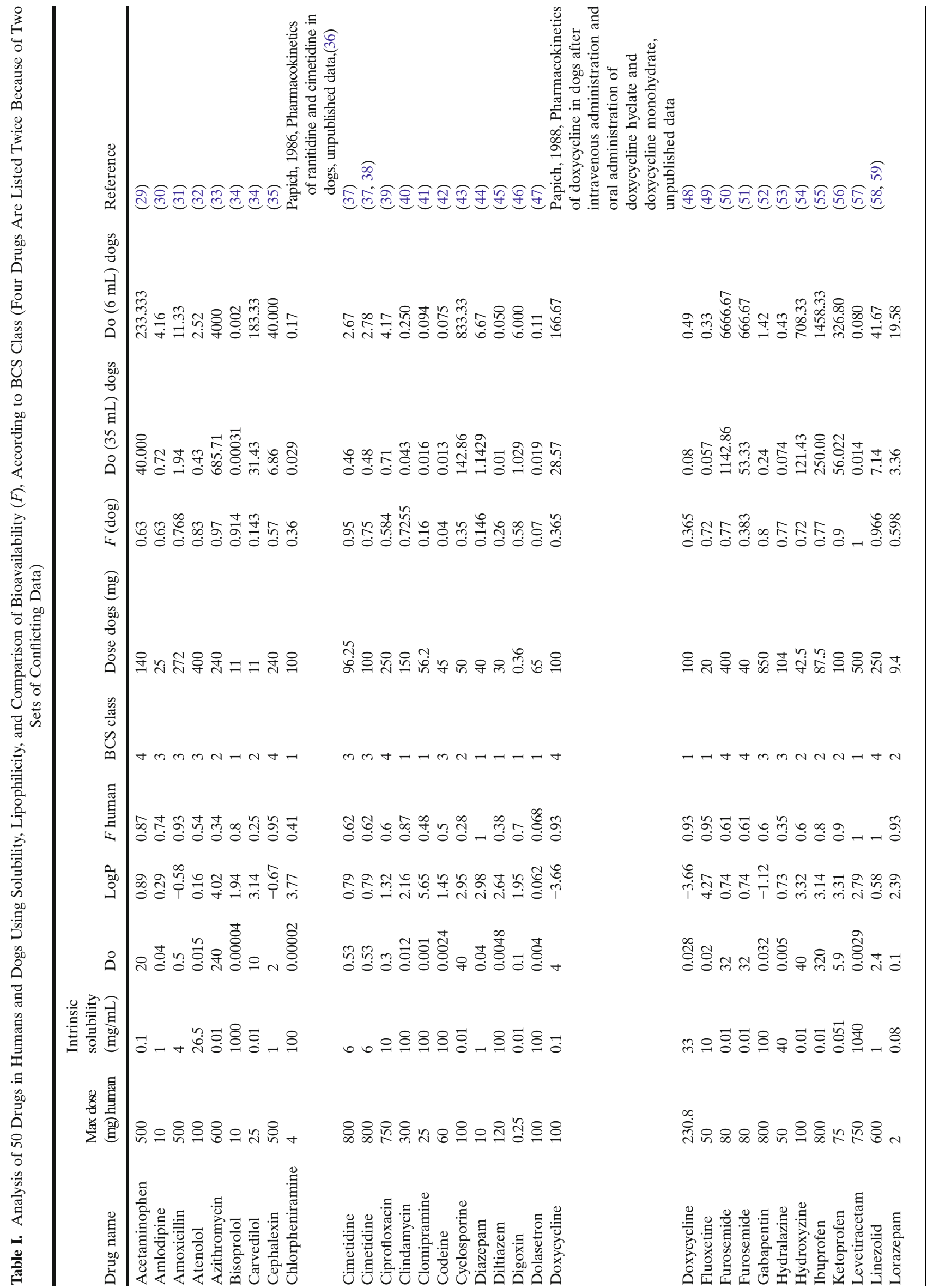




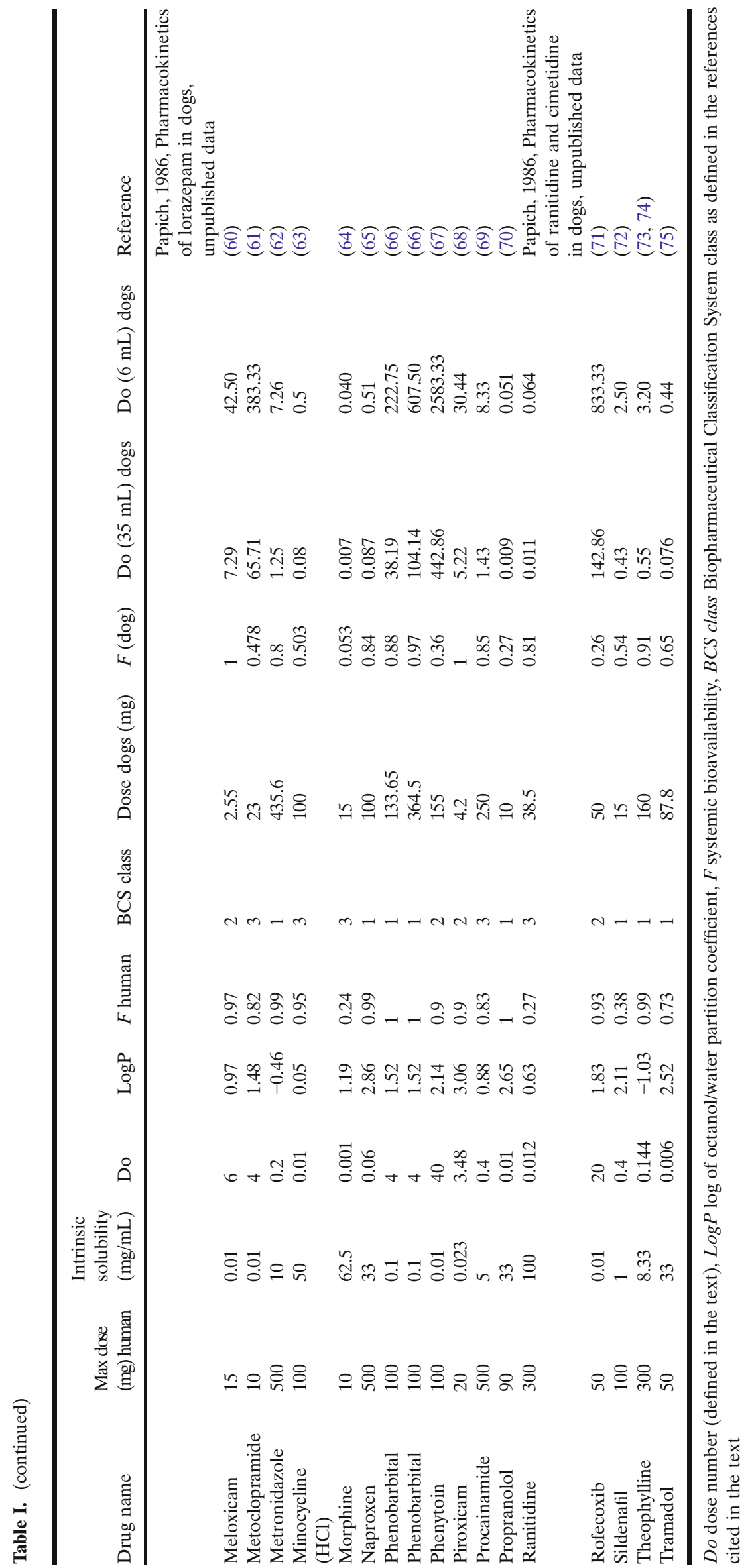




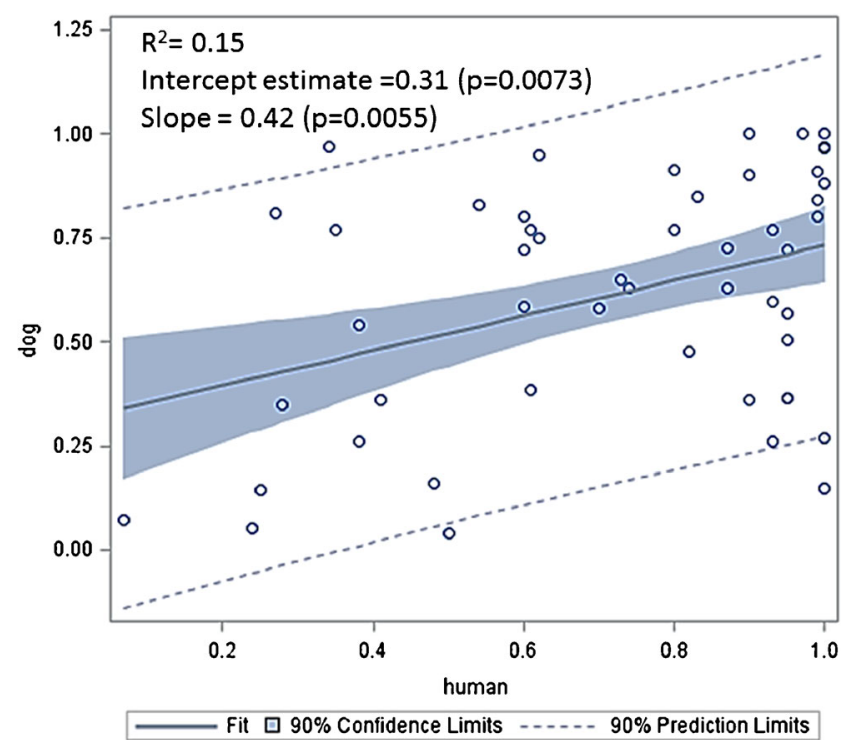

Fig. 1. The relationship between oral bioavailability $(F)$ observed in humans versus dogs. Although there was much variability in the relationship between estimated values of $F$ in dogs and people, a statistically significant correlation was observed $(p=0.0055)$. The confidence interval (as defined by the shaded region around the regression line) reflects variability both in slope and intercept attributable to the uncertainty in the estimated regression line. While the wider prediction interval likewise reflects the uncertainty of the data, it predicts the interval within which the regression will be contained ( $90 \%$ of the time) if the analysis were repeated using a comparable human and canine populations (i.e., relating the prediction of $\operatorname{dog} F$ from human $F$ ). The intercept $(\operatorname{dog} F$ observed when the human $F=0$ ) is 0.31 , indicating an overall trend toward a higher bioavailability in dogs at very small human values of $F$. The slope of the regression of dog versus human is 0.42

gabapentin, amoxicillin, metronidazole, and theophylline. The Do values in these four drugs ranged from below 0.001 to over 1000 .

To identify some commonality between agents exhibiting high human/canine correlations, we examined the $\mathrm{pKa}$, mechanism of drug elimination (human), and whether or not a human first-pass drug loss was reported (Table II). The vast majority of compounds with similar values of $F$ in dogs and humans were also those compounds with negligible firstpass drug loss. Furthermore, in the three out of four BCS class I compounds where human and canine $F$ values were discordant, those compounds were reported to have a high human first-pass drug loss.

\section{DISCUSSION}

Whether we are providing values for $F$, solubility, permeability, or BCS classification, all values need to be viewed from the perspective as estimates derived under a specific set of experimental conditions. Thus, there are occasions where, for example, a compound was estimated as being within one BCS classification in one reference but as a different class for another reference (e.g., ciprofloxacin). The tables available from Takagi et al. (6) show some of these discrepancies. Similarly, values of $F$ reported within this manuscript reflect a distinct set of experimental conditions, and therefore, there can be differences in reported estimates elsewhere, depending upon study conditions and population. For example, we can consider the compound amlodipine. In one study, the human oral bioavailability was stated to be $63 \%$ (30). However, in the Pfizer monograph for amlodipine besylate (http://www.pfizer.ca/en/our_products/products/ monograph/212), the absolute bioavailability of an oral administration ranged between 64 and 90\%. Accordingly, on an individual compound basis, the estimated ratio of dog and human $F$ values provided in this manuscript should be considered a single point within a distribution of potential estimates. That said, when viewed across a diverse library of compounds (as we have done in this manuscript), these values provide a tool for examining variables that can be used to examine interspecies relationships in drug absorption.

Highly soluble and highly permeable compounds will likely exhibit similar oral drug bioavailabilities unless the drug exhibits differing extent of first-pass metabolism in dogs versus humans. Nevertheless, we cannot conclude that a drug's BCS classification will necessarily translate across species. BCS solubility classifications are traditionally based upon a calculation of the Do, which assumes a dissolution volume of $250 \mathrm{~mL}$ (approximately one cup of water). That volume is far greater than the gastric volume of the fasted dog. Typically, studies performed in dogs will include a water flush of 6 or $12 \mathrm{~mL}$ because, for practical reasons, these are common plastic syringe sizes. We included a high value of $35 \mathrm{~mL}$ in our analysis because this represents the equivalent to the $250 \mathrm{~mL}$ ( one cup) in humans scaled to the size of an average Beagle dog (the breed used most often in oral drug absorption studies). Accordingly, compounds considered highly soluble in a human population may not meet the criteria for highly soluble in dogs. Regardless of whether we consider the canine gastric volume to be 6 or $35 \mathrm{~mL}$, we found that the solubility classification would be affected for only a few compounds (Fig. 3a, b). Using a Do cutoff of 1.0 for distinguishing between low or high solubility compounds, only seven drugs, gabapentin, cimetidine, amlodipine, ciprofloxacin, sildenafil, theophylline, and atenolol, would have had a different solubility classification as a function of different volumes used for these calculations. In some cases, this solubility difference may impact oral drug absorption. For example, in the case of ciprofloxacin, Papich (39) observed that differences in the volume administered with the oral dose may indeed affect $F$ in dogs. When ciprofloxacin tablets were administered with a volume that decreased the Do below 1, oral absorption was better than when the Do was $>1$. This observation points to the importance of dosing regimens and study design when interpreting study data.

Another challenge facing interspecies BCS extrapolations is that by convention, a drug is classified as highly soluble based upon the highest administered dose. In the case of diazepam, the drug itself is poorly soluble, but may be listed as a human BCS class I compound because of the low administered dose. The importance of considering dose was underscored with diazepam where our cited canine investigations used a dose of $40 \mathrm{mg}$ (i.e., approximately $4 \mathrm{mg} / \mathrm{kg}$ ). This is in contrast with a $10-\mathrm{mg}$ dose in humans (i.e., approximately $0.14 \mathrm{mg} / \mathrm{kg}$ for a $70-\mathrm{kg}$ person). Thus, although included in the list of BCS class I compound for this analysis, it would have been 
a

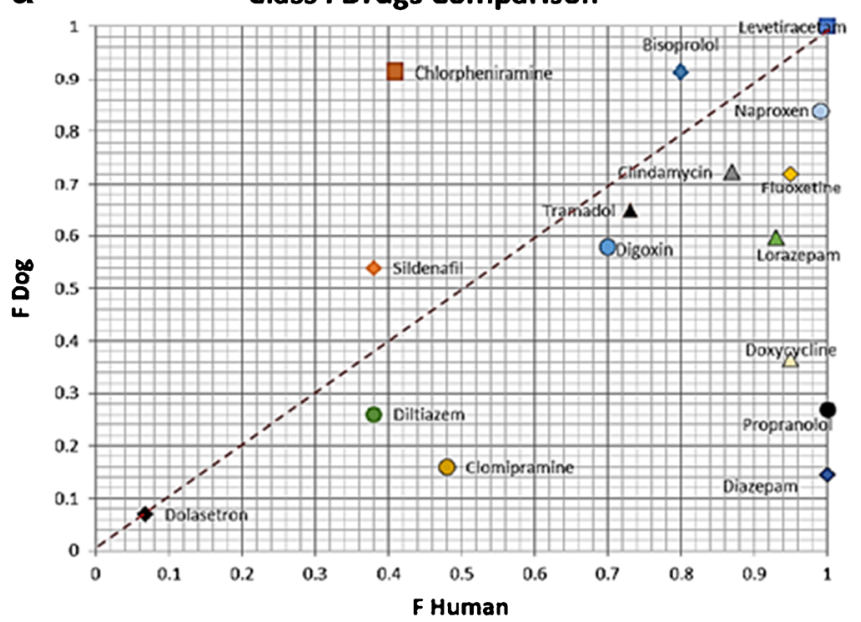

b

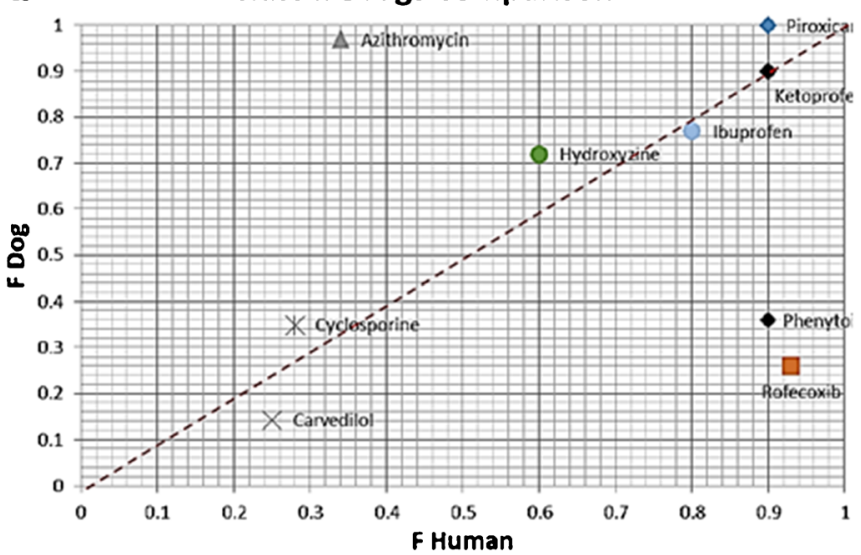

C Class III Drugs Comparison

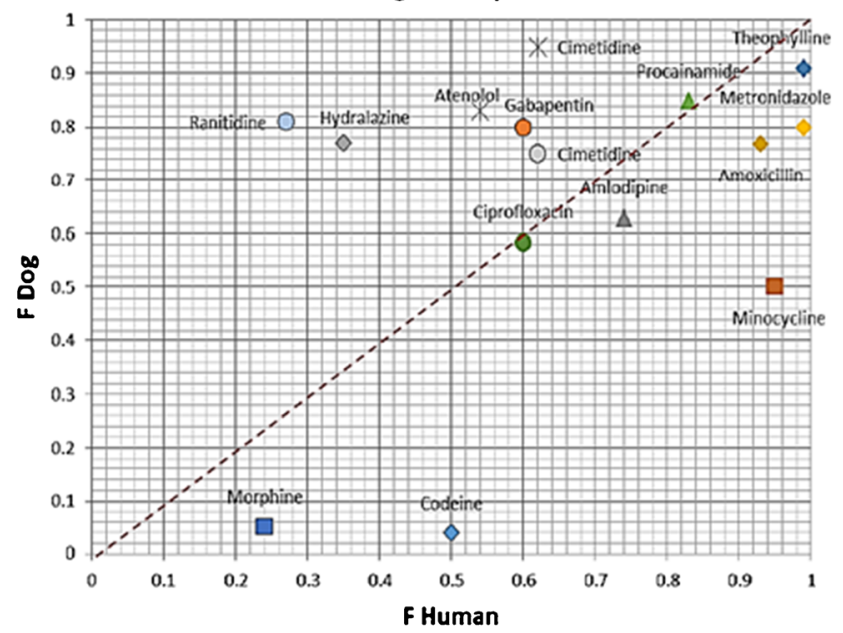

d

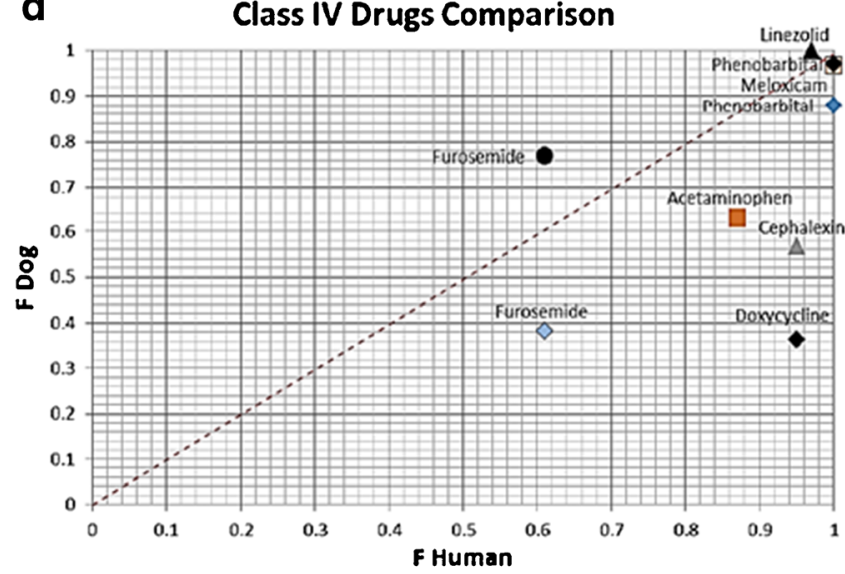

Fig. 2. Comparison of canine/human absolute bioavailability $(F)$ as a function of human BCS classification: a BCS class I compounds, $\mathbf{b}$ BCS class II compounds, $\mathbf{c}$ BCS class III compounds, and d BCS class IV compounds. The hatched line represents the theoretical line of unity

more appropriate to have classified diazepam as a BCS class II drug (at least for the sake of the canine investigation). Diazepam was in the lower right quadrant of the group of class I drugs (Fig. 2a), and considering the low solubility of diazepam, it is not surprising that its oral bioavailability was very poor in dogs where tablet dissolution is further compromised by a rapid GI transit time (vide infra).

The BCS classification is influenced by the ability of the highest dose strength to be fully solubilized in $250 \mathrm{~mL}$ ( one cup) of aqueous media over the $\mathrm{pH}$ range of 1-7.5. However, for low solubility compounds, interspecies differences in absorbable dose may also be impacted by the composition of the GI fluids. In this regard, the unique composition of canine GI fluid can lead to differences in canine-human in vivo tablet dissolution (77).

Because dissolution impacts oral bioavailability, it is important to distinguish between criteria used to evaluate the inherent solubility of the active pharmaceutical ingredient (API) versus that used to characterize in vivo dissolution of a dosage form. As compared to an assessment of the API, the dissolution rate (DR) of any formulated product is a function of its available surface area $(A)$, the diffusion coefficient $(D)$ of the drug (i.e., its ability to move from the undissolved portion of the API to the surrounding dissolution medium, the effective boundary layer thickness ( $h$, which is the water that physically surrounds the undissolved API), the saturation concentration of the API under the conditions of the dissolution test (Cs), the amount of drug already dissolved $(\mathrm{Xd})$, and the volume of fluid $(V)$ within which the dissolution must occur (78). From an interspecies perspective, differences in GI fluid volume and composition can have an effect on most of these variables. These interrelationships are described by the Noyes-Whitney equation (23):

$\mathrm{DR}=\frac{A \times D}{h} \times \mathrm{Cs}-\frac{\mathrm{Xd}}{V}$

These considerations will be particularly important for low solubility compounds and may further complicate efforts to generate interspecies comparisons based upon the bioavailability of solid oral dosage forms.

Another challenge facing an examination of canine BCS criteria is that of defining what constitutes a high versus low permeability compound. Because there are no commercially available canine cell lines (21), in the absence of in vitro 


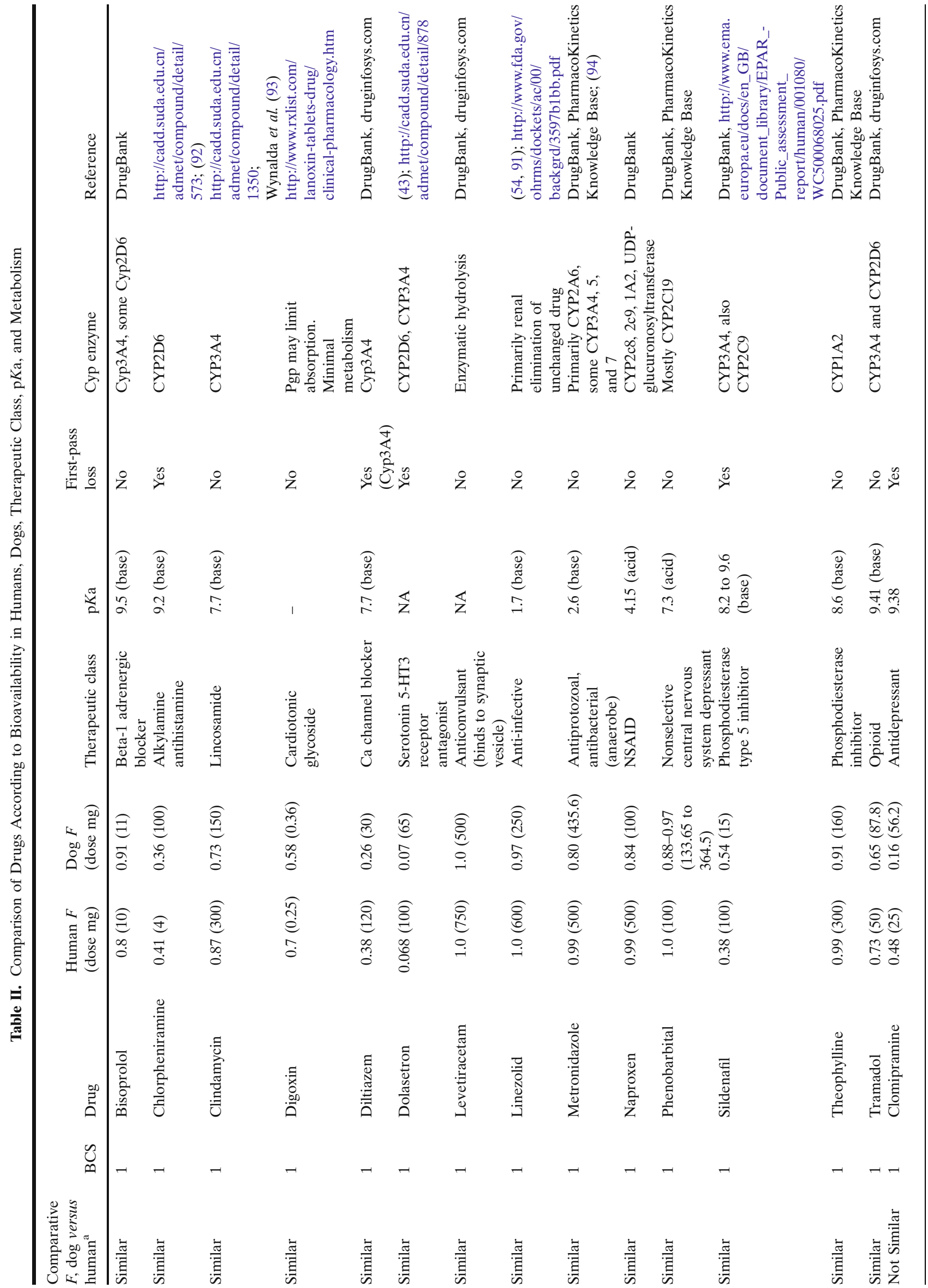




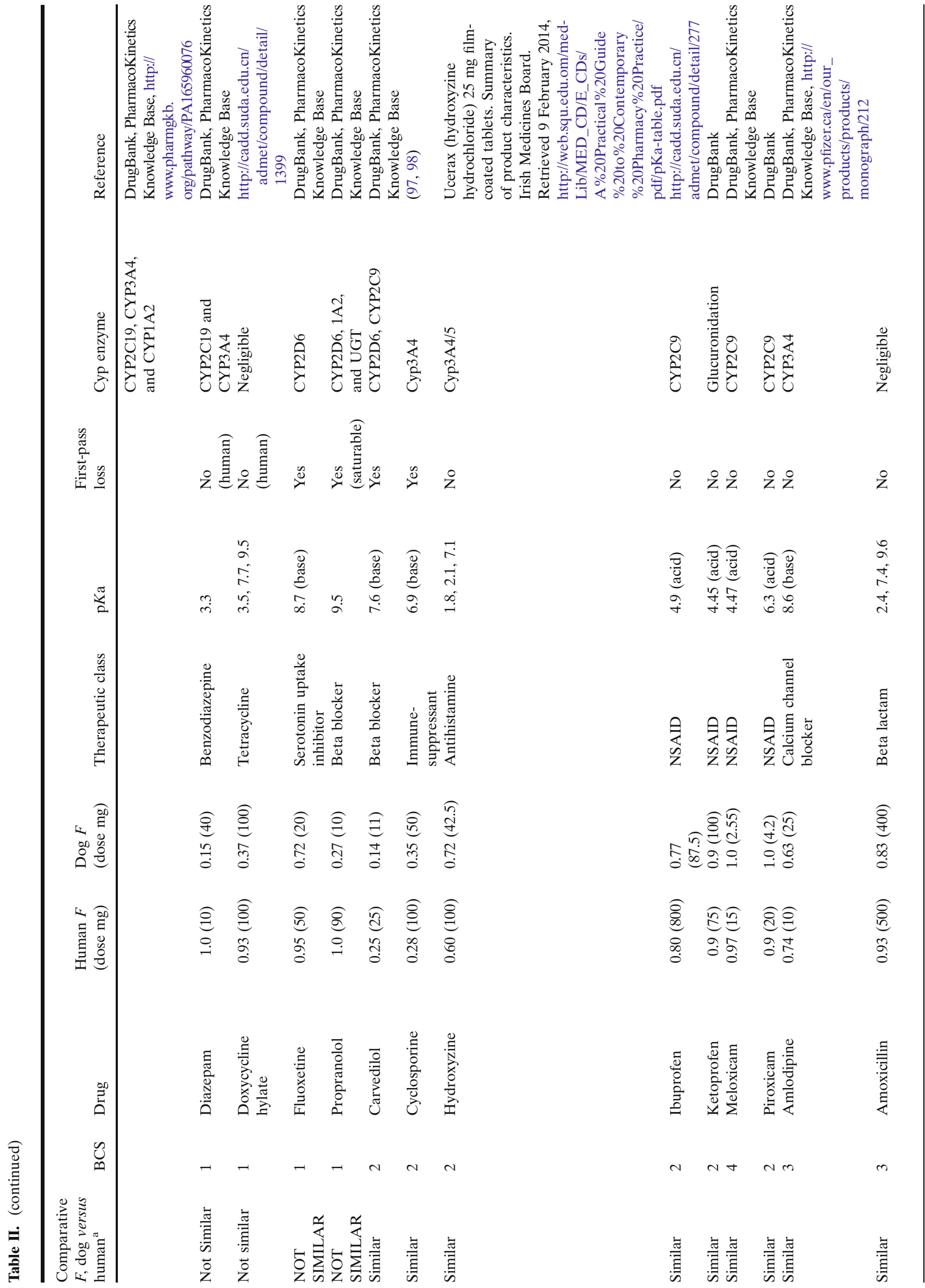




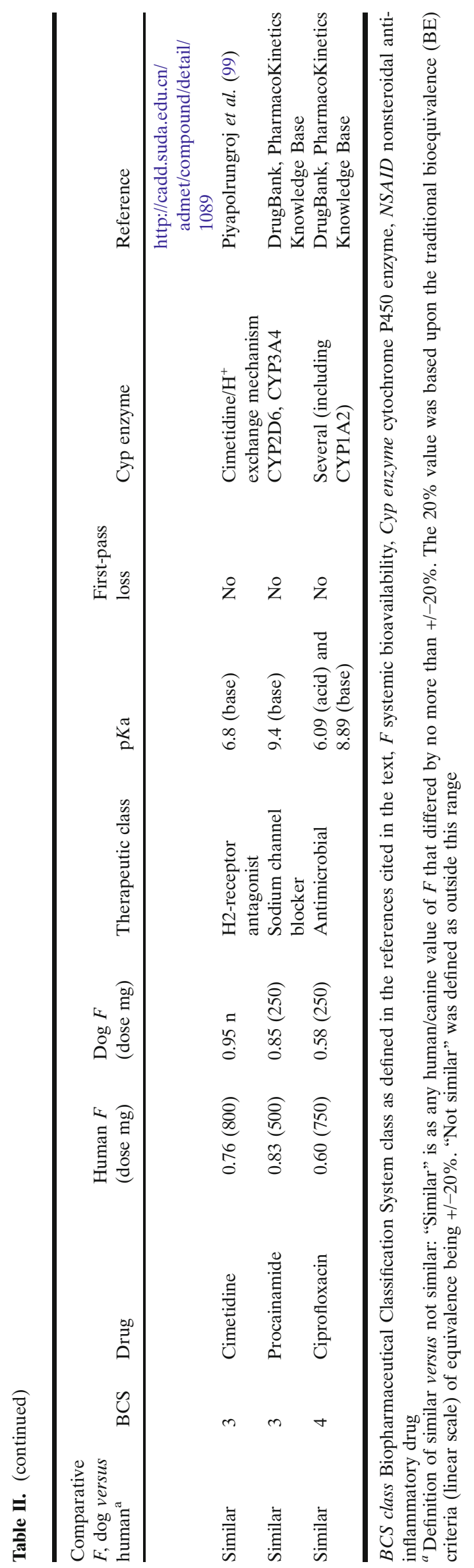


a

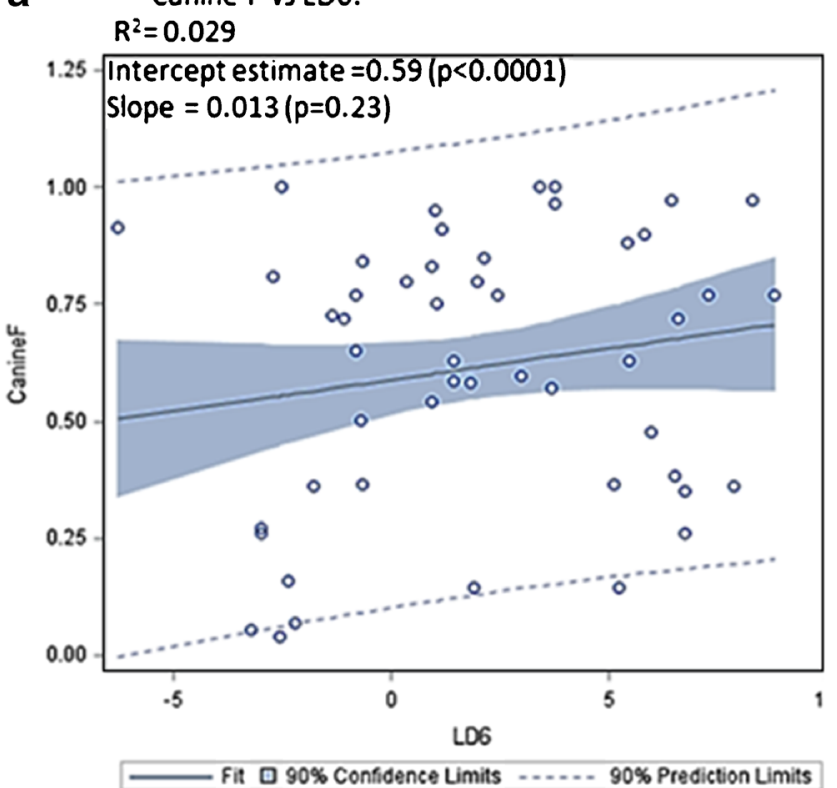

b

Canine Fvs LD35: $R^{2}=0.031$

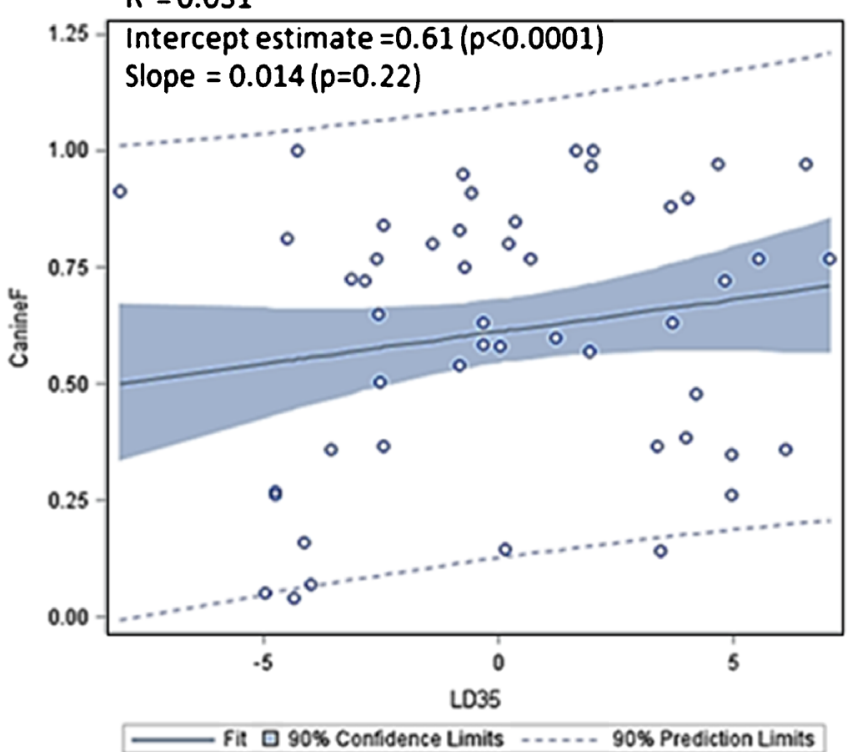

Fig. 3. The influence of the log-transformed dose number $(L D)$ on the estimated value of $F$ in dogs. a The relationship defined by volume of 6 $\mathrm{mL}$ (LD6). b The relationship defined by a volume of $35 \mathrm{~mL}$ (LD35). Interpretation of confidence versus prediction intervals corresponds with that previously described for Fig. 1

permeability data, we have relied upon $\log P$ values as the basis for estimating a canine BCS permeability cutoff value. Our selection of $\log \mathrm{P}$ values was founded upon published reports where $\log \mathrm{P}$ was used as a surrogate for human permeability studies (3-6). These referenced studies used metoprolol, with a $\log \mathrm{P}=1.72$ as the reference standard for the cutoff between high/low permeability. Drugs with $\log \mathrm{P}>1.72$ are classified as highly permeable, while those with $\log \mathrm{P}<1.72$ are classified as low permeability $(5,6)$. Our literature search did not produce any canine pharmacokinetic data for oral metoprolol. However, we did have information on a similar $\beta$-adrenergic antagonist, bisoprolol, which has chemical characteristics similar to that of metoprolol (BCS class 1, low Do, and $\log P 1.94$ ) and greater than $90 \%$ oral absorption in dogs (34), suggesting that we could rely upon the human LogP cutoff of 1.72 for our canine assessments.

We failed to observe a correlation between a $\operatorname{LogP}$ cutoff value of 1.72 versus those drugs having high or low $F$ values in dogs (Fig. 4). In fact, a line drawn at a $\log P$ of 1.72 would practically split this group of drugs down the middle. That is, many drugs were found to be highly bioavailable (and therefore presumably highly permeable) whether or not they had LogP values above or below 1.72. Likewise, we identified several BCS class III drugs (high solubility, low permeability) with $F$ values as high, or higher in dogs as compared to humans (Fig. 2c).

In the absence of first-pass drug loss, further study will help to determine whether or not the use of $\operatorname{LogD}$ (which is based upon both ionized and unionized species, i.e., is a $\mathrm{pH}$ dependent value) rather than $\log P$ would have been a more appropriate metric because $\log \mathrm{D}$ values better reflect the impact of GI pH on human-canine permeability differences. For compounds with molecular weights ranging from 165 to 644 , the relationship between the Caco-2 cell-based apparent permeability (Papp) and $\log \mathrm{D}$ values were described by a bell-shaped relationship (22). Highly permeable compounds (i.e., those with Papp values of $100-340 \mathrm{~nm} \mathrm{~s}^{-1}$ ) had $\operatorname{LogD}$ values ranging between 0 and 3 , while low permeability compounds had values of either less than -1.5 or greater than

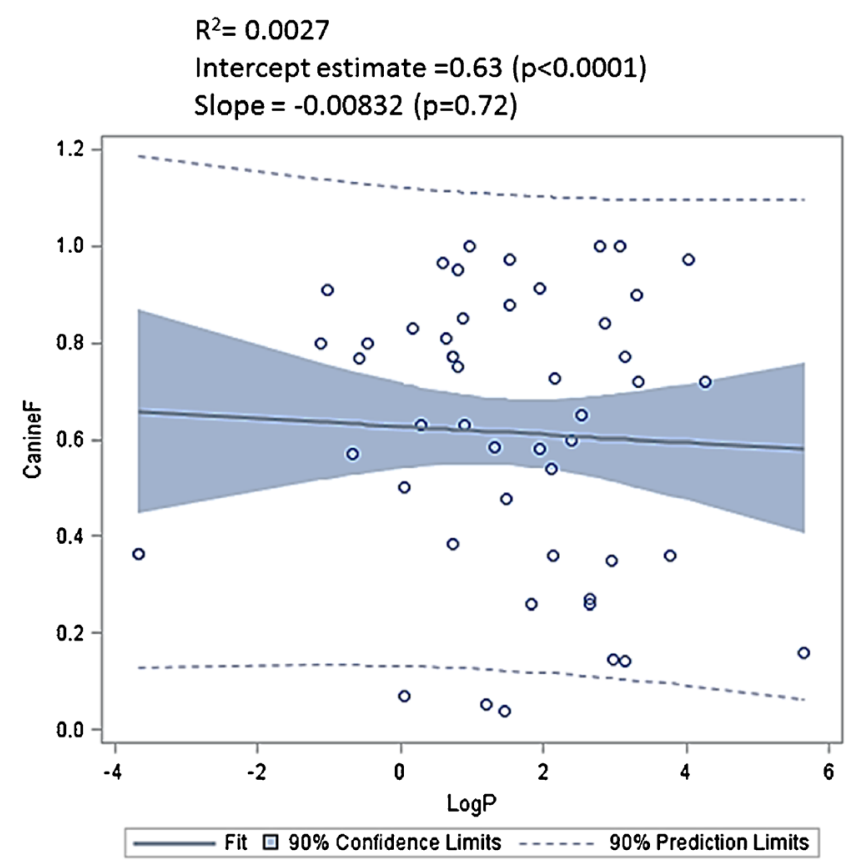

Fig. 4. $\log \mathrm{P}$ value versus $F$ value in dogs for 50 drugs. $\log P$ is the experimentally determined lipid partition coefficient; the $F$ value is the bioavailability in dogs. The estimated canine $F$ value when $\log \mathrm{P}$ is zero is 0.62 . The corresponding slope of the line is -0.008 . The large $P$ value indicates that this is not a significant correlation, and therefore, the negative slope should not be construed as being indicative of any true relationship. Interpretation of confidence versus prediction intervals corresponds with that previously described for Fig. 1 
High F (>80\%) Drugs in Dogs

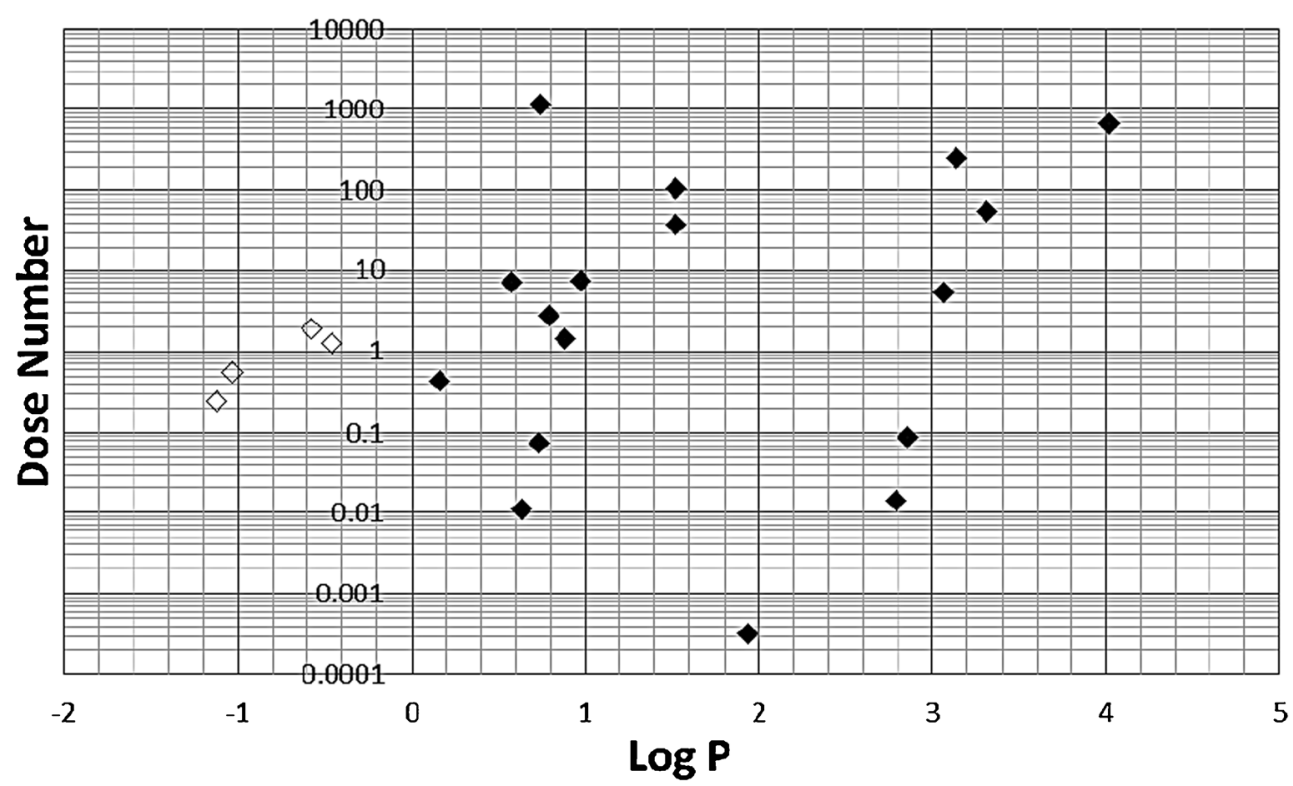

Fig. 5. High bioavailability (approximately $80 \%$ ) drugs in dogs compared to dose number and $\log$ P. (Dose number and LogP were previously defined.) Four drugs (shown with open diamonds on the left side of the figure) were exceptions because they had $\log \mathrm{P}<0$, but good bioavailability: metronidazole, which is a small molecule absorbed paracellularly in dogs; gabapentin and amoxicillin, which are probably absorbed via intestinal transporters; and theophylline, which can be absorbed from the large intestine (colon)

4.5. However, Kramer (22) observed that the reliability of $\log \mathrm{D}$ for estimating permeability appears to diminish when the molecular weight exceeds 500, and additional variables impacting permeability (e.g., hydrogen bonding properties, molecular size and shape, polarity, and flexibility) may need to be examined.

When considering the compounds where we have identified dog-human disparities in $F$, presystemic drug metabolism is likely to be an important factor to consider. This was seen in the drugs that fell below the line of unity in Fig. 2a-d, where several of these agents are known to be highly metabolized in dogs. There are also compounds (cyclosporine, carvedilol, dolasetron, and diltiazem) that were associated with high first-pass drug loss but had similar human-canine values of $F$. Therefore, an identification of pathways (e.g., CYP450 metabolizing enzymes, uptake and efflux transporters) responsible for the presystemic drug loss may help predict those drugs for which there is likely to be interspecies bioavailability differences.

Presystemic drug loss is a likely reason for some of the differences in the interspecies relationship described by Chiou et al. (26) as compared to that reported in this current study. In particular, canine oral bioavailability in this study was either similar to or lower than that reported by Chiou and colleagues. They (26) reported values based upon urinary concentrations of total drug, but the studies used in our analysis analyzed only the parent compound, typically using HPLC methods. We believe that the trend toward lower bioavailability in our dataset likely reflects differences in gut or hepatic presystemic metabolism in the dog.

Although one ordinarily anticipates a low $F$ for poorly permeable drugs, there were two BCS class III and IV compounds with human $F>0.90$ (amoxicillin and cephalexin).
Despite their poor membrane permeability, both compounds undergo active transport via peptide transporter 1 (PEPT1) (79-81). Thus, enterocyte penetration via facilitated/active rather than passive processes will result in an extent of absorption that cannot be predicted solely on the basis of BCS classification criteria. Moreover, numerous BCS class III and IV compounds were associated with an $F>0.80$ in dogs but not in humans. It is undetermined why these drugs defined as poorly permeable exhibited such high $F$ values in dogs. Because the dog intestine is anatomically shorter than that of humans, in order to absorb nutrients, the canine intestine may have evolved a greater capacity for intestinal uptake transport as compared to that of humans. Less active intestinal efflux transport also is possible. For low molecular weight compounds, there is also greater paracellular absorption for some compounds in dogs than humans (18) (vide infra).

For furosemide, there was higher bioavailability from a 400-mg dose ( $F$ 0.77) compared to a tenfold lower dose of $40 \mathrm{mg}$ ( $F$ 0.38). Class III and IV drugs ordinarily typically do not exhibit saturable drug efflux (82). But for this class IV compound, efflux transport apparently can be saturated at high doses, thus increasing its oral bioavailability (83-85). Therefore, it would seem likely that at the high doses of furosemide administered in the canine study, an increase in enterocyte concentrations produced a saturation of efflux transporters and a corresponding larger $F$.

When drugs with relatively high $F$ values in dogs were considered (Fig. 5), most of those compounds were associated with $\log \mathrm{P}$ values $>0$. The only drugs in this study that showed both high $F$ values in $\operatorname{dogs}$ and $\log \mathrm{P}<0$ were gabapentin, amoxicillin, metronidazole, and theophylline-all class III drugs that were in the upper right quadrant of Fig. 2c. In 
these cases, the high $F$ in dogs, despite low $\log \mathrm{P}$, can be explained by other factors. Gabapentin and amoxicillin rely on intestinal influx transporters for their absorption. Metronidazole and theophylline are small molecules (molecular weight 171 and 198, respectively) that can be absorbed via paracellular pathways. Drugs of low molecular weight are likely to be absorbed from the intestine via the paracellular pathway rather than by transcellular diffusion. Dogs have larger pore size and a greater frequency of pores in the intestine compared to that observed in other species (18). This difference in pore number and diameter may have contributed to the observed greater oral absorption irrespective of the compound's Peff value. Furosemide is another example of a drug for which paracellular absorption has a significant impact $(83,84)$ and where the differences between $F$ in humans and dogs may reflect the competing effects of paracellular versus transcellular absorption and efflux transport of those molecules that did successfully enter into the enterocyte.

Some of the BCS class III compounds such as morphine and codeine (high solubility, low permeability) had lower $F$ in dogs than in humans (Fig. 2c). For these compounds, the marked interspecies difference in oral bioavailability is the result of a high first-pass metabolism in dogs $(42,64)$, a characteristic of oral opiates in dogs that is not as prominent in humans. Other oral opiates not included in this analysis also have essentially zero oral systemic availability in dogs $(86,87)$. For these drugs, systemic clearance exceeds liver blood flow and there may be extrahepatic metabolism contributing to the high first-pass metabolism.

For lipophilic compounds (BCS class II and IV), solubilization can be significantly impacted by bile salt composition and excretion. If the bile salt-drug interactions result in micelle formation, the resulting encapsulation can lead to a decrease in drug transport, limiting the ability of free drug to move across a biological membrane (88). The formation of micelles can either increase or decrease drug absorption, depending upon the magnitude of its impact on solubility versus permeability (89). A micellar-induced increase in the solubility of lipophilic compounds (due to endogenous, food-associated, or formulation-associated surfactants) can increase or decrease drug intestinal permeability (90) by reducing the partition coefficient between the intraluminal fluid and the biological membrane (91). Thus, the $\mathrm{pH}$ and composition of GI fluids can be pivotal to doghuman differences in the absorption of lipophilic molecules.

The analysis presented in this paper reveals some challenges and pitfalls of relying on the human BCS parameters to predict performance of oral drug products in dogs. Because the BDDCS also takes into consideration presystemic drug metabolism, the combination of the BCS and BDDCS criteria for evaluating oral drugs in dogs may be a better approach to examine human/ canine differences in oral bioavailability than the use of a single classification system. This approach is consistent with the perspective explained by Shugarts and Benet (82) where they note that the BDDCS considers the major route of elimination as an important factor in classification instead of permeability. As emphasized by Shugarts and Benet (82), "BCS cannot predict absorption," which is what we observed in this study. The BDDCS divides drugs into four classes based on solubility (high or low, as in the BCS), and whether or not the drug has low, or extensive metabolism. Because permeability data is difficult to acquire for medications in dogs, and because the $\log P$ reference values used to assess human GI permeability do not appear to predict oral absorption for dogs, a system such as the BDDCS or some new system for dogs should be explored.

We are continuing in our effort to examine the specific factors that explain the observed human-canine differences in oral drug absorption. When considering sources of potential interspecies divergence, the important physiologic variables include GI fluid $\mathrm{pH}$ and composition, intestinal transit time, mucosal surface area, and the size and density of intestinal intercellular pores (92-95). These factors are particularly influential in the absorption of low solubility and/or low permeability drugs and may be helpful to predict interspecies differences in food effects (96). Further considerations into metabolic pathway and influx/efflux transporter activity needs to be incorporated into our overall assessment. It is with these points in mind that we have summarized the important variables to incorporate into our human-canine interspecies extrapolations (Table II).

\section{CONCLUSION}

This investigation showed that applying the same BCS criteria to dogs and humans can be problematic. At least in part, when attempting to designate a BCS classification for dogs, there is a need to develop canine-specific solubility and permeability assessments. Ultimately, even when the necessary in vitro methods for estimating canine drug solubility and permeability have been developed, canine-human physiological differences can result in marked differences in systemic absorption due to transporter functions, drug metabolism, and the leakier canine intestinal membranes.

Clearly, there remains much work to be done in order to improve our ability to predict drug absorption in the dog when based upon preliminary drug physicochemical characterization and an interspecies extrapolation of in vivo PK information. Efforts to predict drug absorption (or to understand the causative factors impacting interspecies differences in $F$ ) is dependent upon a wide array of variables including API solubility and permeability (BCS), formulation factors, and physiological variables (including regional permeability differences, which could differ between species), GI $\mathrm{pH}$, luminal and mucosal enzymology, and intestinal motility, first-pass drug metabolism, and transporter activity (92-96). It is for this reason that a blending of BCS and the BDDCS may provide far better predictions of canine versus human drug absorption characteristics than would either classification system alone. Comparing drug absorption characteristics in dogs and humans, while important for interspecies extrapolations and for formulation development, also provides valuable insights into the variables that can influence drug absorption (and interindividual differences) that can occur in the presence of human or canine GI pathologies, breed potential breed effects on canine drug absorption, or the changes in drug absorption that may occur in the geriatric dog or human population. Such predictions are predicated largely upon the development of mechanistic (in silico) models. By understanding the impact of these critical variables on the rate and extent of drug absorption, these models can be positioned for use in predicting the canine to human (and vice 
versa) differences in oral drug absorption and in vivo product performance.

Our ongoing efforts are based upon the use of this drug list to explore published human-canine differences in drug metabolism, along with an evaluation of other potential variables. We anticipate that through these efforts, we will obtain a better appreciation of the pivotal factors dictating in vivo product absorption and determine potential sources of error when attempting to extrapolate information obtained in humans to support in silico predictions of in vivo drug absorption characteristics in dogs.

At the time this manuscript was prepared, we did not have access to the paper published by Musther et al. (100). Their paper included 125 paired datasets comparing $\mathrm{F}$ between dogs and humans and included many of the same studies that were used in our analysis. As we report here, they also found a poor correlation in $\mathrm{F}$ for drugs between dogs and humans with an R value of 0.37 . Musther et al. (100) did not include BCS criteria in their analysis, but instead, separated compounds into acidic, basic, neutral, or zwitterions. This improved the prediction slightly for acidic drugs, some of which were likely BCS class II compounds. A prediction model of human $\mathrm{F}$ from canine values, based on a linear regression model, resulted in wide prediction intervals with a low concordance correlation coefficient (precision of the prediction), confirming the lack of agreement between human and $\operatorname{dog} \mathrm{F}$ values. As in our studies, they found that Beagle dogs were represented more often than other dog breeds for bioavailability determination in most studies (66\%). We encountered similar problems as described by Musther et al. (100) when extracting data from published studies. Some studies provided full details of the methods and results and others provided limited data. They concluded, as we did, that metabolic differences between species could play a more important role in defining disparities between human and animal drug bioavailability.

\section{ACKNOWLEDGMENTS}

The authors would like to thank Robyn Martinez for her help collecting data for this manuscript. They also appreciate the support from the United States Pharmacopeia in the early stages of this project. The authors also acknowledge the advice and recommendations from Dr. G.L. Amidon and Dr. James Polli in the analysis of these data.

Conflicts of Interest The authors have no conflicts of interest to disclose.

\section{REFERENCES}

1. Martinez MN, Papich MG, Riviere JE. Veterinary application of in vitro dissolution data and the biopharmaceutics classification system. Stimuli to the revision process. Pharmacopeial Forum (United States Pharmacopeial Convention) 30(6): 2-10, 2004.

2. Amidon GL, Lennernäs H, Shah VP, Crison JR. A theoretical basis for a biopharmaceutic drug classification: the correlation of in vitro drug product dissolution and in vivo bioavailability. Pharm Res. 1995;12:413-20.
3. Lindenberg M, Kopp S, Dressman JB. Classification of orally administered drugs on the World Health Organization model list of essential medicines according to the biopharmaceutics classification system. Eur J Pharm Biopharm. 2004;58:265-78.

4. Lennernäs H, Abrahamsson B. The use of biopharmaceutic classification of drugs in drug discovery and development: current status and future extension. J Pharm Pharmacol. 2005;57:273-85.

5. Kasim NA, Whitehouse M, Ramachandran C, Bermejo M, Lennernas H, Hussain AS, et al. Molecular properties of WHO essential drugs and provisional biopharmaceutical classification. Mol Pharm. 2004;1:85-96.

6. Takagi T, Ramachandran C, Bermejo M, Yamashita S, Yu LX, Amidon GL. A provisional biopharmaceutical classification of the top 200 oral drug products in the United States, Great Britain, Spain, and Japan. Mol Pharma. 2006;3(6):631-43.

7. Wu CY, Benet LZ. Predicting drug disposition via application of BCS: transport/absorption/elimination interplay and development of a biopharmaceutics drug disposition classification system. Pharm Res. 2005;22:11-23.

8. Benet LZ. The role of BCS (biopharmaceutics classification system) and BDDCS (biopharmaceutics drug disposition classification system) in drug development. J Pharm Sci. 2013;102(1):34-42.

9. FDA Guidance For Industry, CDER, "Waiver of in vivo bioavailability and bioequivalence studies for immediate-release solid oral dosage forms based on a biopharmaceutics classification system", 2000.

10. Heikkinen AT, Fowler S, Gray L, Li J, Peng Y, Yadava P, et al. In vitro to in vivo extrapolation and physiologically based modeling of cytochrome P450 mediated metabolism in beagle dog gut wall and liver. Mol Pharm. 2013;10(4):1388-99.

11. Box KJ, Völgyi G, Baka E, Stuart M, Takács-Novák K, Comer JE. Equilibrium versus kinetic measurements of aqueous solubility, and the ability of compounds to supersaturate in solution-a validation study. J Pharm Sci. 2006;95(6):1298-307.

12. Venkatesh S, Li J, Xu Y, Vishnuvajjala R, Anderson BD. Intrinsic solubility estimation and $\mathrm{pH}$-solubility behavior of cosalane (NSC 658586), an extremely hydrophobic diprotic acid. Pharm Res. 1996;13(10):1453-9.

13. Takács-Novák, K. Solubility-pH profile of drugs. Experiences and surprises in $\operatorname{logS}$ measurements, Semmelweis University, Budapest, Phys Chem FORUM 9 September 17, 2010.

14. Teksin ZS, Seo PR, Polli JE. Comparison of drug permeabilities and BCS classification: three lipid-component PAMPA system method versus Caco-2 monolayers. AAPS J. 2010;12(2):238-41.

15. Buckley ST, Fischer SM, Fricker G, Brandl M. In vitro models to evaluate the permeability of poorly soluble drug entities: challenges and perspectives. Eur J Pharm Sci. 2012;45(3):235-50.

16. Balimane PV, Chong S, Morrison RA. Current methodologies used for evaluation of intestinal permeability and absorption. J Pharmacol Toxicol Methods. 2000;44:301-12.

17. Pelkonen O, Boobis AR, Gundert-Remy U. In vitro prediction of gastrointestinal absorption and bioavailability: an experts' meeting report. Eur J Clin Pharmacol. 2001;57:621-9.

18. He Y-L, Murby S, Warhurst G, Gifford L, Walker D, Ayrton J, et al. Species differences in size discrimination in the paracellular pathway reflected by oral bioavailability of poly(ethylene glycol) and D-peptides. J Pharm Sci. 1998;87(5):62633.

19. Rubas W, Jezyk N, Grass GM. Comparison of the permeability characteristics of a human colonic epithelial (Caco-2) cell line to colon of rabbit, monkey, and dog intestine and human drug absorption. Pharm Res. 1993;10:113-8.

20. Davis JL, Little D, Blikslager AT, Papich MG. Mucosal permeability of water-soluble drugs in the equine jejunum: a preliminary investigation. J Vet Pharmacol Ther. 2006;29(5):379-85.

21. Neirinckx E, Vervaet C, Michiels J, De Smet S, Van Den Broeck W, Remon JP, et al. Feasibility of the Ussing chamber technique for the determination of in vitro jejunal permeability of passively absorbed compounds in different animal species. J Vet Pharmacol Ther. 2011;34(3):290-7. 
22. Kramer, S. Absorption prediction from physicochemical parameters. Pharmaceutical Science and Technology, 1999, 2, 373 \pm 380 .

23. Martinez MN, Amidon GL. A mechanistic approach to understanding the factors affecting drug absorption: a review of fundamentals. J Clin Pharmacol. 2002;42(6):620-43.

24. Martinez MN, Papich MG. Drug solubility classification in the dog. J Vet Pharmacol Ther. 2012;35 Suppl 1:87-91.

25. Apley M, Crist B, Gonzalez MA, Hunter RP, Martinez MN, Modric S, et al. Solubility criteria for veterinary drugs. USP stimuli article. Rockville: United States Pharmacopeia Convention; 2012

26. Chiou WL, Jeong HY, Chung SM, Wu TC. Evaluation of using dog as an animal model to study the fraction of oral dose absorbed for 43 drugs in humans. Pharm Res. 2000;17:135-40.

27. Therapeutic Systems Research Laboratories (TSRL), Inc. Biopharmaceutical Classification System (BCS). Ann Arbor, Michigan. http://www.tsrlinc.com/resources/services/. Accessed 24 Jul 2014.

28. Grabowski T, Jaroszewski JJ. Bioavailability of veterinary drugs in vivo and in silico. J Vet Pharmacol Ther. 2009;32(3):249-57.

29. Sagara K, Mizuta H, Ohshiko M, Shibata M, Haga K. Relationship between the phasic period of interdigestive migrating contraction and the systemic bioavailability of acetaminophen in dogs. Pharm Res. 1995;12(4):594-8.

30. Stopher DA, Beresford AP, Macrae PV, Humphrey MJ. The metabolism and pharmacokinetics of amlodipine in humans and animals. J Cardiovasc Pharmacol. 1988;12 Suppl 7:S55-9.

31. Küng K, Wanner M. Bioavailability of different forms of amoxycillin administered orally to dogs. Vet Rec. 1994;135(23):552-4.

32. McAinsh J, Holmes BF. Pharmacokinetic studies with atenolol in the dog. Biopharm Drug Dispos. 1983;4(3):249-61.

33. Shepard RM, Falkner FC. Pharmacokinetics of azithromycin in rats and dogs. J Antimicrob Chemother. 1990;25(Suppl A):49-60.

34. Beddies G, Fox PR, Papich MG, Kanikanti VR, Krebber R, Keene BW. Comparison of the pharmacokinetic properties of bisoprolol and carvedilol in healthy dogs. Am J Vet Res. 2008;69(12):1659-63.

35. Carli S, Anfossi P, Villa R, Castellani G, Mengozzi G, Montesissa C. Absorption kinetics and bioavailability of cephalexin in the dog after oral and intramuscular administration. J Vet Pharmacol Ther. 1999;22(5):308-13.

36. Athanikar NK, Chiou WL. Chlorpheniramine. II. Effect of the first-pass metabolism on the oral bioavailability in dogs. J Pharmacokinet Biopharm. 1979;7(4):383-96.

37. Jantratid E, Prakongpan S, Dressman JB, Amidon GL, Junginger HE, Midha KK, et al. Biowaiver monographs for immediate release solid oral dosage forms: cimetidine. J Pharm Sci. 2006;95(5):974-84

38. Le Traon G, Burgaud S, Horspool LJI. Pharmacokinetics of cimetidine in dogs after oral administration of cimetidine tablets. J Vet Pharmacol Ther. 2008;32:213-8.

39. Papich MG. Ciprofloxacin pharmacokinetics and oral absorption of generic ciprofloxacin tablets in dogs. Am J Vet Res. 2012;73(7):1085-91.

40. Batzias GC, Delis GA, Athanasiou LV. Clindamycin bioavailability and pharmacokinetics following oral administration of clindamycin hydrochloride capsules in dogs. Vet J. 2005;179:339-45.

41. King JN, Maurer MP, Holz RP, Fisch RD. Pharmacokinetics of clomipramine in dogs following single-dose intravenous and oral administration. Am J Vet Res. 2000;61:74-9.

42. KuKanich B. Pharmacokinetics of acetaminophen, codeine, and the codeine metabolites morphine and codeine-6-glucuronide in healthy Greyhound dogs. J Veterinary Pharmacol Ther. 2009:33:15-21.

43. Novartis Report. Pharmacokinetics of cyclosporine A after intravenous and oral administration to dogs. Novartis internal report, Study CRA 99/141, 2000.

44. Löscher W, Frey H-H. Pharmacokinetics of diazepam in the dog. Arch Int Pharmacodyn Ther. 1981;254:180-95.

45. Yeung PK, Feng JD, Buckley SJ. Effect of administration route and length of exposure on pharmacokinetics and metabolism of diltiazem in dogs. Drug Metabol Drug Interact. 2001;18(34):251-62.

46. Button C, Gross DR, Johnston JT, Yakatan GJ. Pharmacokinetics, bioavailability, and dosage regimens of digoxin in dogs. Am J Vet Res. 1980;41(8):1230-7.

47. Dow J, Francesco GF, Berg C. Comparison of the pharmacokinetics of dolasetron and its major active metabolite, reduced dolasetron, in dog. J Pharm Sci. 1996;85(7):685-9.

48. Jantratid E, Strauch S, Becker C, Dressman JB, Amidon GL, Junginger HE, et al. Biowaiver monographs for immediate release solid oral dosage forms: doxycycline hyclate. J Pharm Sci. 2010;99(4):1639-53.

49. Fluoxetine. Manufacturer's label. Reconcile ${ }^{\circledR}$ (fluoxetine hydrochloride) chewable tablets. INADA \# 141-272. Elanco Animal Health, Indianapolis, IN, USA.

50. El-Sayed MG, Atef M, El-Gendi AY, Youssef SA. Disposition kinetics of furosemide in dogs. Arch Int Pharmacodyn Ther. 1981;253(1):4-10.

51. Lee MG, Chiou WL. Mechanism of ascorbic acid enhancement of the bioavailability and diuretic effect of furosemide. Drug Metab Dispos. 1998;26(5):401-7.

52. Radulovic LL, Türck D, von Hodenberg A, Vollmer KO, McNally WP, DeHart PD, et al. Disposition of gabapentin (neurontin) in mice, rats, dogs, and monkeys. Drug Metab Dispos. 1995;23(4):441-8.

53. Semple HA, Tam YK, Coutts RT. Hydralazine pharmacokinetics and interaction with food: an evaluation of the dog as an animal model. Pharm Res. 1990;7(3):274-9.

54. Bizikova P, Papich MG, Olivry T. Hydroxyzine and cetirizine pharmacokinetics and pharmacodynamics after oral and intravenous administration of hydroxyzine to healthy dogs. Vet Dermatol. 2008;19(6):348-57.

55. Scherkl R, Frey H-H. Pharmacokinetics of ibuprofen in the dog. J Vet Pharmacol Ther. 1987;10:261-5.

56. Schmitt M, Guentert TW. Biopharmaceutical evaluation of ketoprofen following intravenous, oral, and rectal administration in dogs. J Pharma Sci. 1990;79:614-6.

57. Moore SA, Muñana KR, Papich MG, Nettifee-Osborne J. Levetiracetam pharmacokinetics in healthy dogs following oral administration of single and multiple doses. Am J Vet Res. 2010;71(3):337-41.

58. Slatter JG, Stalker DJ, Feenstra KL, Welshman IR, Bruss JB, Sams JP, et al. Pharmacokinetics, metabolism, and excretion of linezolid following an oral dose of [(14)C]linezolid to healthy human subjects. Drug Metab Dispos. 2001;29(8):1136-45.

59. Slatter JG, Adams LA, Bush EC, Chiba K, Daley-Yates PT, Feenstra KL, et al. Pharmacokinetics, toxicokinetics, distribution, metabolism, and excretion of linezolid in mouse, rat, and dog. Xenobiotica. 2002;32:907-24.

60. Busch U, Schmid J, Heinzel G, Schmaus H, Baierl J, Huber C, et al. Pharmacokinetics of meloxicam in animals and the relevance to humans. Drug Metab Dispos. 1998;26(6):576-84.

61. Bateman DN, Kahn C, Davies DS. The pharmacokinetics of metoclopramide in man with observations in the dog. Br J Clin Pharmacol. 1980;9:371-7.

62. Neff-Davis CA, Davis LE, Gillette EL. Metronidazole: a method for its determination in biological fluids and its disposition kinetics in the dog. J Vet Pharmacol Ther. 1981;4(2):121-7.

63. Maaland MG, Guardabassi L, Papich MG. Minocycline pharmacokinetics and pharmacodynamics in dogs: dosage recommendations for treatment of meticillin-resistant Staphylococcus pseudintermedius infections. Vet Dermatol. 2014;25(3):182. e47.

64. KuKanich B, Lascelles BD, Papich MG. Pharmacokinetics of morphine and plasma concentrations of morphine-6glucuronide following morphine administration to dogs. J Vet Pharmacol Ther. 2005;28(4):371-6.

65. Frey H-H, Rieh B. Pharmacokinetics of naproxen in the dog. Am J Vet Res. 1981;42:1615-7.

66. Pedersoli WM, Wike JS, Ravis WR. Pharmacokinetics of single doses of phenobarbital given intravenously and orally to dogs. Am J Vet Res. 1987;48:679-83.

67. Frey H-H, Löscher W. Clinical pharmacokinetics of phenytoin in the dog: a reevaluation. Am J Vet Res. 1980;41(10):1635-8. 
68. Galbraith EA, McKellar QA. Pharmacokinetics and pharmacodynamics of piroxicam in dogs. Vet Rec. 1991;128:561-5.

69. Papich MG, Neff-Davis CA, Davis LE, McKiernan BC, Brown SA. Pharmacokinetics of procainamide in dogs. Am J Vet Res. 1986;47:2351-8.

70. Tse FL, Sanders TM, Reo JP. Bioavailability of propranolol in the dog. Arch Int Pharmacodyn Ther. 1980;248(2):180-9.

71. Halpin RA, Geer LA, Zhang KE, Marks TM, Dean DC, Jones $\mathrm{AN}$, et al. The absorption, distribution, metabolism and excretion of rofecoxib, a potent and selective cyclooxygenase2 inhibitor, in rats and dogs. Drug Metab Dispos. 2000;28(10):1244-54.

72. Walker DK, Ackland MJ, James GC, Muirhead GJ, Rance DJ, Wastall $\mathrm{P}$, et al. Pharmacokinetics and metabolism of sildenafil in mouse, rat, rabbit, dog and man. Xenobiotica. 1999;29(3):297-310.

73. McKiernan BC, Neff-Davis CA, Koritz GD, Davis LE, Pheris DR. Pharmacokinetic studies of theophylline in dogs. J Vet Pharmacol Ther. 1981;4:103-10.

74. Bach JE, Kukanich B, Papich MG, McKiernan BC. Evaluation of the bioavailability and pharmacokinetics of two extendedrelease theophylline formulations in dogs. J Am Vet Med Assoc. 2004;224(7):1113-9.

75. KuKanich B, Papich MG. Pharmacokinetics and antinociceptive effects of oral tramadol hydrochloride administration in Greyhounds. Am J Vet Res. 2011;72(2):256-62.

76. Benet LZ, Broccatelli F, Oprea TI. BDDCS applied to over 900 drugs. AAPS J. 2011;13(4):519-47.

77. Arndt M, Chokshi H, Tang K, Parrott NJ, Reppas C, Dressman JB. Dissolution media simulating the proximal canine gastrointestinal tract in the fasted state. Eur J Pharm Biopharm. 2013;84(3):633-41.

78. Dressman JB, Reppas C. In vitro-in vivo correlations for lipophilic, poorly water-soluble drugs. Eur J Pharm Sci Suppl. 2000;2:S73-80.

79. Bretschneider B, Brandsch M, Neubert R. Intestinal transport of beta-lactam antibiotics: analysis of the affinity at the $\mathrm{H}+$ /peptide symporter (PEPT1), the uptake into Caco-2 cell monolayers and the transepithelial flux. Pharm Res. 1999;16(1):55-61.

80. Ranaldi G, Islam K, Sambuy Y. D-cycloserine uses an active transport mechanism in the human intestinal cell line Caco 2. Antimicrob Agents Chemother. 1994;38(6):1239-45.

81. Westphal JF, Jehl F, Brogard JM, Carbon C. Amoxicillin intestinal absorption reduction by amiloride: possible role of the $\mathrm{Na}(+)-\mathrm{H}+$ exchanger. Clin Pharmacol Ther. 1995;57(3):257-64.

82. Shugarts S, Benet LZ. The role of transporters in the pharmacokinetics of orally administered drugs. Pharm Res. 2009;26:2039-54.

83. Flanagan SD, Takahashi LH, Liu X, Benet LZ. Contributions of saturable active secretion, passive transcellular, and paracellular diffusion to the overall transport of furosemide across adenocarcinoma (Caco-2) cells. J Pharm Sci. 2002;91(4):1169-77.

84. Flanagan SD, Cummins CL, Susanto M, Liu X, Takahashi LH, Benet LZ. Comparison of furosemide and vinblastine secretion from cell lines overexpressing multidrug resistance protein (Pglycoprotein) and multidrug resistance-associated proteins (MRP1 and MRP2). Pharmacology. 2002;64(3):126-34.

85. Al-Mohizea AM. Influence of intestinal efflux pumps on the absorption and transport of furosemide. Saudi Pharm J. 2010;18(2):97-101.

86. Kukanich B, Papich MG. Plasma profile and pharmacokinetics of dextromethorphan after intravenous and oral administration in healthy dogs. J Vet Pharmacol Ther. 2004;27(5):337-41.

87. Kukanich B, Lascelles BD, Aman AM, Mealey KL, Papich MG. The effects of inhibiting cytochrome P450 3A, p-glycoprotein, and gastric acid secretion on the oral bioavailability of methadone in dogs. J Vet Pharmacol Ther. 2005;28(5):461-6.

88. Ingels F, Beck B, Oth M, Augustijns P. Effect of simulated intestinal fluid on drug permeability estimation across Caco-2 monolayers. Int J Pharm. 2004;274(1-2):221-32.

89. Miller JM, Beig A, Krieg BJ, Carr RA, Borchardt TB, Amidon GE, et al. The solubility-permeability interplay: mechanistic modeling and predictive application of the impact of micellar solubilization on intestinal permeation. Mol Pharm. 2011;8(5):1848-56.

90. Markopoulos C, Imanidis G, Vertzoni M, Symillides M, Parrott N, Reppas C. In vitro and ex vivo investigation of the impact of luminal lipid phases on passive permeability of lipophilic small molecules using PAMPA. Pharm Res. 2013;30(12):3145-53.

91. Brouwers J, Augustijns P. Resolving intraluminal drug and formulation behavior: gastrointestinal concentration profiling in humans. Eur J Pharm Sci. 2014. doi:10.1016/j.ejps.2014.01.010.

92. Dressman JB. Comparison of canine and human gastrointestinal physiology. Pharm Res. 1986;3:123-31.

93. Wynalda MA, Hutzler JM, Koets MD, Podoll T, Wienkers LC. In vitro metabolism of clindamycin in human liver and intestinal microsomes. Drug Metab Disp. 2003;31(7):878-887.

94. Martinez MN, Papich MG. Factors influencing the gastric residence of dosage forms in dogs. J Pharm Sci. 2009;98(3):844-60. Review.

95. Kararli TT. Comparison of the gastrointestinal anatomy, physiology, and biochemistry of humans and commonly used laboratory animals. Biopharm Drug Dispos. 1995;16:351-80.

96. Sabnis S. Factors influencing the bioavailability of peroral formulations of drugs for dogs. Vet Res Commun. 1999;23:425-47.

97. Kolars JC, Awni WM, Merion RM, Watkins PB. First pass metabolism of cyclosporin by the gut. Lancet. 1991;338(8781):1488-90.

98. Oliyai R, Stella VJ. Kinetics and mechanism of isomerization of cyclosporin A. Pharm Res. 1992;9(5):617-22.

99. Piyapolrungroj N, Li C, Pisoni RL, Fleisher D. Cimetidine transport in brush-border membrane vesicles from rat small intestine. JPET. 1999;289(1):346-353.

100. Musther H, Olivares-Morales A, Hatley OJD, Liu B, Hodjegan AR. Animal versus human oral bioavailability: Do they correlate? Eur J Pharm Sci. (2014);57: 280-291. 